\title{
PERBAIKAN MANAJEMEN BERBASIS TEKNOLOGI PADA CV TIMAN AGUNG KLATING KERAMBITAN TABANAN
}

\author{
N.W. Siti ${ }^{1}$ N.M. Witariadi² ${ }^{2}$ N.N.Soniari ${ }^{3}$ dan N. K. Seminari ${ }^{4}$
}

\begin{abstract}
ABSTRAK
Pengabdian bertujuan untuk meningkatkan pengetahuan dan keterampilan karyawan CV Timan Agung Klating, Kerambitan Tabanan dalam mengelola manajemen berbasis teknologi. CV Timan Agung yang telah berjalan 10 tahun, telah merintis usahanya dibidang pupuk biorganik padat, cair dan inokulan. Namun manajemen CV Timan Agung masih tumpang tindih, oleh karena itu pendampingan ini dilaksanakan untuk membantu memeperbaiki manajemen CV Timan Agung. Metode yang dilakukan antara lain mengadakan penyuluhan dan pelatihan dibidang manajemen yang memanfaatkan teknologi, menyusun struktur organisasi CV Timan Agung, melatih seluruh karyawan CV Timan Agung sesuai bidangnya dan membenahi kantor sesuai fungsinya. Hasil dari pendampingan adalah, CV Timan Agung telah memiliki struktur organisasi yang terpampang di kantor CV Timan Agung. Pembukuan yang dimiliki CV Timan Agung telah memanfaatkan teknologi computer yang sebelumnya di susun secara manual, sudah mempunyai softwere akutansi. Peruntukan bangunan seperti kantor, lahan produksi gudang, dan parkir telah tertata dengan jelas. Dari hasil pengabdian dapat dismpulkan bahwa CV Timan Agung sudah memiliki kantor dilengkapi dengan struktur organisasi dan satu paket computer yang sudah berisi softwere serta pegawai adminstrasi.
\end{abstract}

Kata kunci : CV Timan Agung, Pelatihan Manajemen, Teknologi

\begin{abstract}
Devotion aims to improve the knowledge and skills of employees of CV Timan Agung Klating, Keambitan Tabanan in improving technology-based management. CV Timan Agung, which has been running for 10 years, has pioneered its business in the field of solid, liquid and inoculant organic fertilizer. However, CV Timan Agung's management still overlaps, therefore this assistance is carried out to help improve CV Timan Agung's management. The methods carried out include conducting counseling and training in management that utilizes technology, arranging the organizational structure of CV Timan Agung, training all employees of CV Timan Agung according to their fields and fixing the office according to their functions. As a result of the assistance, CV Timan Agung has an organizational structure posted on the Timan Agung CV office. From this structure employees understand what their duties and responsibilities are. Bookkeeping owned by CV Timan Agung has utilized computer technology that was previously compiled manually. Allotments of buildings such as offices, warehouse production areas and parking lots are clearly arranged.
\end{abstract}

Keywords: Timan Agung CV, Training, Management, Technology

\footnotetext{
${ }^{1}$ Dosen Program Studi Sarjana Peternakan Fakultas Peternakan Universitas Udayana, wayansiti@unud.ac.id

2.Dosen Program Studi Sarjana Peternakan Fakultas Peternakan Universitas Udayana, witarimade@yahoo.com

${ }^{3}$ Dosen Program Studi Agroekoteknologi Fakultas Pertanian Universitas Udayana,nengahsonari@unud.ac.id

${ }^{4}$ Dosen Program Studi Manajemen Fakultas Pertanian dan Bisnis Universitas udayana,ktseminari@unud.ac.id
} 
https://elearning.unud.ac.id/course/view.php?id=771

\section{PENDAHULUAN}

CV. Timan Agung merupakan perusahaan yang bergerak khusus sebagai produsen pupuk organik dan biopestisida. Pada awalnya perusahan ini berupa kelompok tani ternak sistem pertanian terintegrasi atau Simantri yang berdiri tahun 2009 dengan jumlah anggota sebanyak 40 orang, dengan usaha pemeliharaan sapi (penggemukan dan bibit) dan pengolahan pupuk dari limbah kotoran sapi. Dalam perkembangannya, kelompok ini pada tahun 2010 membentuk sebuah Perusahan dengan ijin SIUP dari Dinas Perindustrian dan Perdagangan bernomor 517/16/PM/BR/BPMPD, dengan nama CV. Timan Agung. Bahan baku utama UKM ini dalam memproduksi pupuk organik selain kotoran ternak adalah dekomposer yang masih terpaku kepada EM4 sehingga sangat tergantung kepada ketersediaan bahan tersebut dipasaran, baik menyangkut jumlah, kualitas dan harga. Selain itu, kinerja dari dekomposer ini relatif kurang optimal. Penyediaan dekomposer yang inovatif yang lebih efektif dengan kandungan mikroba yang lebih lengkap serta mampu diproduksi sendiri sangat penting bagi peningkatan produktivitas usaha. Kemampuan memproduksi stater/decomposer secara mandiri tidak saja menurunkan ketergantungan terhadap pasokan stater/decomposer tersebut dipasaran juga dapat menekan biaya produksi

CV. Timan Agung merupakan pemasok utama pupuk organik di Propinsi Bali, baik untuk kebutuhan pupuk subsidi pemerintah maupun kebutuhan pasar umum. Untuk memenuhi pasar kebutuhan subsidi pemerintah yang jumlahnya banyak dan dalam waktu yang relatif bersamaan baik dalam penyediaan bahan baku maupun pupuk jadi, CV. Timan agung bekerjasama dengan kelompok Sistem Pertanian Terintegrasi (SIMANTRI) yang berjumlah 12 kelompok. Pola kerjasama menyerupai model inti plasma, dimana CV. Timan Agung sebagai inti dan Kelompok Simantri sebagai plasma. Pihak inti berperan sebagai pengepul dan agen yang melakukan kontrak dagang dengan istansi pemerintah dalam pemasaran. Pihak inti melakukan supervisi mengenai proses produksi dan terapan teknologi serta kontrol kualitas produk plasma agar sesuai dengan standar mutu yang diminta oleh pembeli. Sementara plasma bertindak sebagai pemasok bahan baku dan produk jadi kepada perusahaan inti. Keseluruhan produk berlabel produksi CV. Timan Agung. Oleh sebab itu, difusi teknologi perguruan tinggi tidak saja berdampak bagi CV. Timun Agung melainkan juga bagi kelompok Simantri yang tersebar luas di Kabupaten Tabanan. UKM ini sudah mendapat pembinaan dan bantuan peralatan dari beberapa dinas, diantaranya dari Dinas Pertanian Kabupaten Tabanan, Dinas Perindustrian dan Perdagangan Kabupaten Tabanan, Dinas Pertanian Provinsi Bali, Kementerian Riset dan Teknologi Jakarta dan Kementerian Pertanian Jakarta.

CV Timan Agung belum mempunyai manjemen yang berbasis computer, semua pembelian, penjualan masih dilakukan secara manual. Demikian pula kantor belum layak, ruangan masih bergabung dengan ruang produksi, tempat parker belum tertata masih bergabung dengan gudang, jdi barang keluar masuk menjadi terhambat. CV Timan Agung belum mempunyai struktur organisasi secara tertulis, bukti pembayaran masih manual, dan belum mempunyai tenaga administrasi secara khusus. Karyawan belum mempunyai tugas secara jelas seperti yang menjadi Manajer merangkap jadi tenaga produksi, yang menjadi marketing merangkap jadi bendahara, demikian juag yang menjadi tenaga administrasi merangkap jadi tenaga produksi. Ruang produksi CV Tiamn Agung masih bergabung antara kantor, produk pupuk organik padat, biopestisida cair dan produk inokulan sehingga karyawan kurang nyaman dalam melaksanakan pekerjaan. Demikian juga hasil produk baik pupuk biorganik padat, biopestisida dan inokulan kualitasnya menjadi menurun.

Berdasarkan uraian di atas maka UKM CV Timan Agung perlu didampingi dalam memperbaiki manajemen produksi seperti membuat kantor terpisah dengan ruang produksi, membuat struktur 
organisasi, menata parker dan membuat pembukuan berbasis teknologi computer. Melalui pendampingan ini manajemen CV Timan Agung menjadi lebih baik.

\section{METODE PELAKSANAAN}

Metode yang digunakan adalah (1) penyuluhan yang meliputi manajemen peroduksi seperti membuat struktur organisasi, membuat SOP Produk, Pengemasan Produk, Pemasaran, pembuatan softwere, menata kantor, ruang produksi dan parker. (2) Pendampingan dalam membuat struktur organisasi, membuat SOP Produk, Pengemasan produk, pendampingan membuat pembukuan berbasis computer, menata ruang kantor, ruang produksi dan parker.

Perbaikan dilakukan antara lain dengan mengadakan pendidikan dan pelatihan dibidang manajemen yang memanfaatkan teknologi. Bidang manajemen yang dilatih yaitu manajemen produksi, pemasaran, Sumber DayaManusia (SDM) dan keuangan. Bidang manajemen produksi lebih kepada penataan lay out proses produksi yaitu penempatan bahan baku proses produksi hingga penenpatan produk akhir. Bidang pemasaran yaitu produk, harga distribusi dan promosi. Untuk bidang SDM yaitu Menyusun struktur organisasi CV TimanAgung, melatih seluruh Karyawan CV TimanAgung sesuai bidangnya. Memperbaiki kantor sesuai fungsinya, Sedangkan dibidang manajemen keuangan untuk CV Timan Agung akan mulai membuat pembukuan yang teratur dengan menggunakan program berupa software yang memuat berbagai catatan keuangan.

\section{HASIL DAN PEMBAHASAN}

Kegiatan pengabdian yang berjudul Perbaikan Manajemen berbasis Teknologi pada CV Timan Agung, telah dilaksanakan mulai dari bulan Mei sampai Oktober 2019. Kegiatan yang dilakukan meliputi: penyuluhan dan pendampingan manajemen produksi. Penyuluhan manajemen produksi dilaksanakan tanggal 20-22 Juni 2019. Materi penyuluhan meliputi : manajemen produksi, pemasaran, sumber daya manusia dan keuangan. Pendampingan dilakukan mulai dari 5 Juli sampai Oktober 2019. Hasil dari pendampingan meliputi (1) terwujudnya gudang untuk tempat membuat inokulan dan produk inikulan, (2) kantor sudah terpisah dengan gudang dan sudah dilengkapi dengan rak tempat file, lemari untuk tempat pajangan produk, (3) Struktur organisasi yang sudah dipasang di kantor dan (4) satu paket computer yang telah dilengkapi dengan software yang sudah berisi tentang akunting dari CV Timan Agung. CV Timan Agung sudah mempunyai satu tenaga adminsitrasi khusus untuk melayani penjualan, pajak, surat keluar dan masuk. Pelatihan manajemen produksi meliputi SOP produksi pupuk padat dan cair yang tidak boleh dilanggar, karena berpengaruh terhadap kualitas pupuk. Pelatihan manajemen pengemasan meliputi teknik pengemasan agar menarik diisi kandungan nutrisi dari pupuk padat dan cair, manfaat dari pupuk tersebut, takaran pemakaiannya dan untuk tanaman keras, atau pot serta gambar yang menarik. Marketing dilatih agar percaya diri dalam memasarkan produk serta memahami teknologi yang digunakan dalam memproduksi produk, agar pembeli yakin bahwa produk yang dijual menggunakan teknologi yang tepat sesuai dengan keperluan untuk pertanian dan peternakan. Pelatihan softwere diikuti oleh 2 tenaga administrasi satu untuk menangani pajak, surat masuk dan keluar, yang lagi satu untuk menangani akuntansinya. Pelaksanaan kegiatan di CV

Timan Agung dapat dilihat pada Gambar 3.1;3.2 ;3.3;3.4;3.5 dan 3.6.

\section{KESIMPULAN DAN SARAN}

Kesimpulan yang bisa diambil dari kegiatan pengabdian hi-link adalah: (1) Tingkat pengetahuan karyawan CV Timan Agung manajemen produksi meningkat, (2) Terwujudnya Struktur Organisasi CV Timan Agung, (3) terwujudnya gudang untuk membuat produk inokulan, kantor sudah terpisah dengan gudang produksi pupuk, tempat parker sudah dipagar dan (4) terwujudnya softwere untuk akutansinya. Melalui pedampingan manajemen produksi, penjualan produk CV Tiamn Agung menjadi meningkat. 
Pelaksanaan kegiatan pengabdian ini dapat dilahat pada Gambar 3.1-3.6
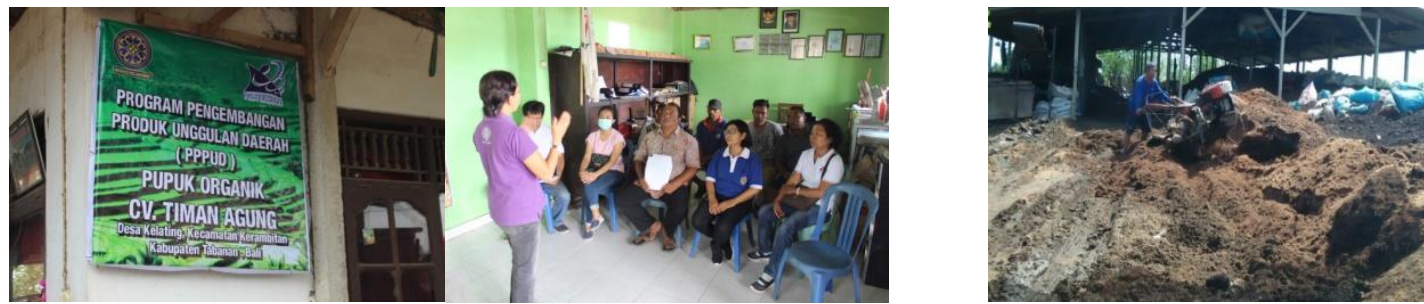

Gambar 3.1 Penyluhan Manajemen Produk di CV Timan Agung, Klating Tabanan

Gambar 3.2. Pencampuran bahan baku pupuk

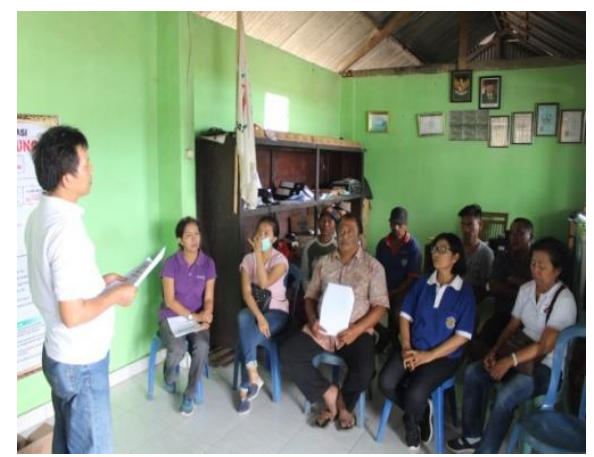

Gambar3.3 Pelatihan Softwere

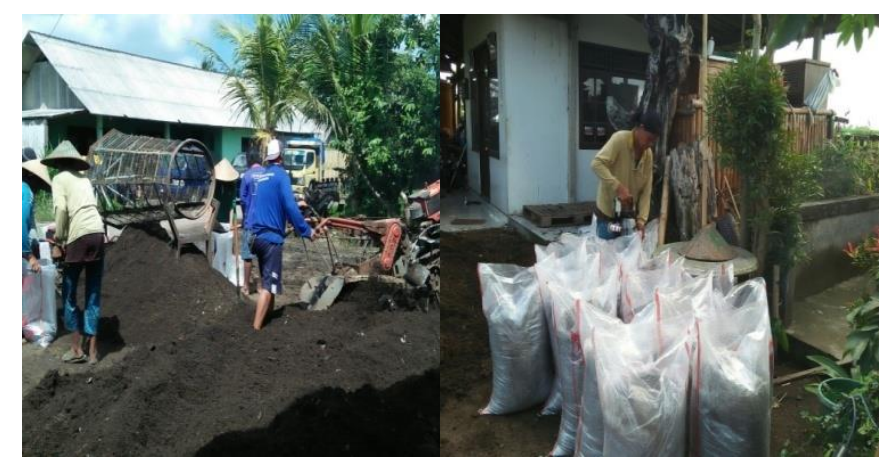

Gambar 3.4 Pengemasan Pupuk
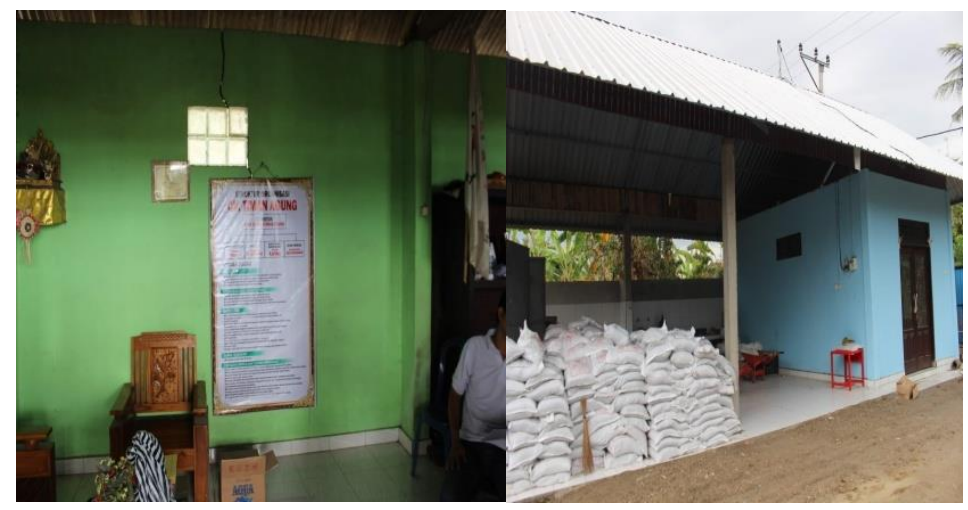

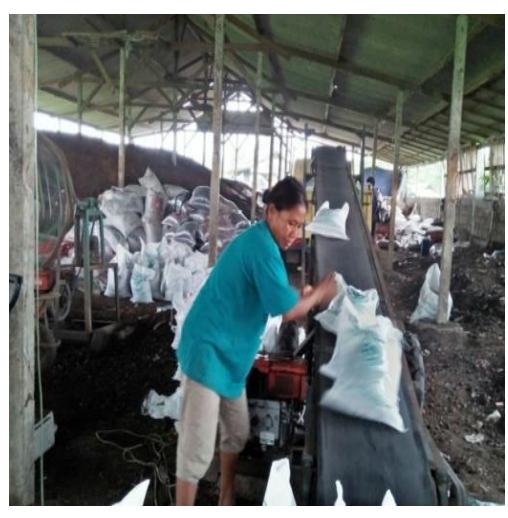

Gambar 3.5. Kantor baru dan Struktur organisasi serta Gudang Baru
Gambar 3.6. Pupuk siap didistribusikan

\section{UCAPAN TERIMA KASIH}

Penulis mengucapkan terima kasih kepada KEMENRISTEK DIKTI atas dana yang diberikan lewat Program Pengembangan Produk Unggulan Daerah (PPPUD), Rektor Universitas Udayana, Ketua LPPM beserta staf terima kasih atas seleksi proposal dan tenaga yang diberikan dalam pelaksanaan di lapangan, sehingga pengabdian kepada masyarakat terlaksana sesuai rencana.

\section{DAFTAR PUSTAKA}


Baiquni, M. 1999. Participatory Rural Appraisal, Metode dan Teknik Partisipasidalam Pengembangan Perdesaan. Jogjakarta : UGM Press.

Chambers, Robert. 1987 Pembangunan Desa Mulai dari Belakang. (Pepep Sudradjat, penerjemah). Jakarta : LP3ES.

Daldjoeni, N. dan A. Soeyitno. 1978. Pedesaan, Lingkungan, dan Pembangunan. Bandung : Alumni.

David, F. R. 2002. Manajemen Strategis: Konsep. (Terjemahan oleh Sindoro A.). Jakarta: PT. Ikrar Mandiri.

Korten, David C. dan Syahrir. 1988. Pembangunan Berdimensi Kerakyatan. Jakarta : Yayasan obor Indonesia.

Rangkuti, F. 2000. Analisis SWOT: Teknik Membedah Kasus Bisnis. Jakarta: Gramedia Pustaka Utama.

Sumodiningrat, Gunawan. 1999. Pemberdayaan Masyarakat dan Jaring Pengaman Sosial. Jakarta : PT. Gramedia Pustaka Utama.

Suriadikarta, DA dan D Setyorini. 2005. Laporan Hasil Penelitian Standar Mutu Pupuk Organik. Balai Penelitian Ternak, Bogor. 